\title{
Building institutional capacity for environmental governance through social entrepreneurship: lessons from Canadian biosphere reserves
}

\author{
Colleen George ${ }^{1}$ and Maureen G. Reed ${ }^{1}$
}

\begin{abstract}
Sustainability-oriented organizations have typically adopted governance approaches that undertake community participation and collaboration through multistakeholder arrangements. Documented challenges of this model are associated with collaboration and institutional capacity, and include reactive accountability structures, inability to reach consensus, funding limitations, and lack of innovation. Social entrepreneurship is a model used successfully in other social sectors; yet, it has rarely been explored by sustainability-oriented organizations. Nevertheless, research in other sectors has found that social entrepreneurship models of governance can encourage diverse participation from a wide range of social groups. In this paper we consider the value of social entrepreneurship for sustainability-oriented organizations by examining whether it can help address governance-related challenges associated with collaboration and institutional capacity. Analysis of organizational documents and participant interviews in three biosphere reserves in Atlantic Canada revealed that, over time, these organizations have struggled to maintain their mission objectives, retain productivity, and respond to economic stress. By examining social entrepreneurship theory and its practice in a biosphere reserve in northern Quebec, we learned that social entrepreneurship strategies more effectively target values and expertise, encourage meaningful engagement, foster strategic direction, and promote diversified and stable funding models than the stakeholder models explored. We determined there are opportunities to develop hybrid governance models that offer the benefits of social entrepreneurship while addressing the procedural concerns outlined by the stakeholder model.
\end{abstract}

Key Words: biosphere reserves; collaboration; environmental governance; institutional capacity; social entrepreneurship;

\section{INTRODUCTION}

The multistakeholder model of environmental governance has become the most common strategy in North America for engaging citizens. In this model, "stakeholders" and "rights holders" are meant to work together to inform management decisions (Parkins et al. 2006). Stakeholders are described as those affected by or who can affect a decision (Freeman 2010). In Canada, Aboriginal people are considered "rights holders" because they have legal and constitutional rights that are distinct from those of other Canadian citizens. Governments are also rights holders in this sense. The multistakeholder model has been widely adopted in the belief that it offers improved transparency, democracy, equity, and active citizenship and has the potential to reach those who have been marginalized or excluded from top-down decision making (Reed 2008). However, in practice, multistakeholder models have been questioned for reinforcing traditional power structures, restricting opportunities for participation, engendering consultation fatigue, and/or avoiding timely decisions and decisive actions (Singleton 2002, Reed and McIlveen 2006, Parkins and Davidson 2008). Nevertheless, the intention to include multiple stakeholders and points of view is laudable and practical. Hence, many sustainability organizations replicate the basic model of including multiple stakeholders in their own organizational structures to draw on a broad set of knowledge, expertise, and perspectives from within their "communities." However, in the wake of funding cut-backs and reduced volunteerism, nonprofit organizations today face a dual challenge to their internal structures and procedures. They are required to build a governance and organizational culture that can (a) create arenas for broad based participation by stakeholders and rights holders to link ideas, resources, and influence decisions about sustainability, and (b) demonstrate innovation and flexibility in the face of dwindling financial resources. These requirements suggest a need for institutional capacity to harness and mobilize resources to promote organizational change and desired outcomes.

Social enterprise is an alternative model that is increasingly being used by the nonprofit sector (Nicholls 2006). It is based on employing business strategies and innovative approaches to achieve social goals (Granados et al. 2011). Like private entrepreneurs, social entrepreneurs seek innovative opportunities to raise funds; they have aptitudes for innovation and appropriate risk taking. Unlike private enterprise, funds received through nonprofit social enterprise are reinvested in growing the social benefits for stakeholders rather than in securing dividends for shareholders (Kerlin 2013). Two Canadian examples of social enterprises include Evergreen Brick Works in Toronto, Ontario (http://www.evergreen.ca) and Harvest Moon Learning Centre in Clearwater, Manitoba (http://www.harvestmoonsociety.org). Until recently, environmental scholars have been either cautious or unaware of social enterprise. This could be due to the longstanding distrust between private enterprise and environmental practitioners, as well as the belief that meaningful public participation within such enterprises is narrowly conceived (Cropper and Oates 1992, Tietenberg 2002). However, the concept has been advocated for in literature on social innovation and social-ecological systems (SES) because it has the ability to reframe perspectives, identify and engage key stakeholders, and address disagreement (e.g., Biggs et al. 2010). Given a commonality in goals of sustainability organizations and social enterprise, it is appropriate to consider the relative merits of integrating the two models to achieve sustainability objectives. 
Our purpose in this paper is to assess the feasibility, conceptually and empirically, of incorporating key tenets of social entrepreneurship into the governance practices of stakeholderbased sustainability organizations to develop a "hybrid model" that brings together the benefits of both approaches and helps them become more effective players in environmental governance more broadly. We discuss the conceptual foundations of stakeholder and social entrepreneurship models including defining features, history of use, strengths, weaknesses, and opportunities for application. Each is analyzed conceptually through the lens of institutional capacity, defined as the combination of intellectual capital (knowledge resources), social capital (relational resources), and political capital (mobilization potential; after Healey 1998). We provide documentation of case studies of four biosphere reserves (BRs), designated by the United Nations Educational, Scientific and Cultural Organization, located in eastern Québec and Atlantic Canada: ManicouaganUapishka in Québec; Fundy in New Brunswick; Bras d'Or Lakes in Nova Scotia; and Southwest Nova in Nova Scotia. BRs are geographic regions and civil society organizations working at the landscape level to address sustainability challenges by encouraging broad participation of local people in local decisions and actions. The BRs studied have adopted, to various extents, stakeholder and entrepreneurship models of governance. Activities in each BR are evaluated against a framework for institutional capacity to determine the potential for complementary capacity to pursue a holistic agenda for sustainability that might be built by integrating the stakeholder and social entrepreneurship models.

\section{MODEL FOUNDATIONS AND CONTRIBUTIONS TO INSTITUTIONAL CAPACITY}

In organizations employing a stakeholder model, the stakeholders typically make up the board of directors. Each board member is responsible for reflecting and voicing issues of the group s/he represents. In theory, therefore, board members act as "representative" members and should employ strategies to ensure they remain connected to, and informed of, the interests of the groups they serve outside the board. However, in practice, board members may act as "responsible" members, providing a particular point of view based on the perceived best interests of that stakeholder group. Typically, such organizations have staff members who report to the board of directors with their initiatives. Some organizations governed through a stakeholder model are also accountable to government authorities (or sometimes foundations) that provide funding and programmatic direction.

Social enterprises exist to address social or environmental problems by employing business strategies and innovative approaches (Granados et al. 2011). Organizations operating under a social entrepreneurship model are mission driven, and, instead of distributing profits and surpluses among shareholders like traditional entrepreneurs, social entrepreneurs working under a not-for-profit model reinvest revenue into their mission with aims of reducing their dependence on external sources of funding (Kerlin 2013). Social enterprises usually have a large number and variety of stakeholders because they need to account for a variety of interests, and ensure they have the expertise and contacts necessary to operate successfully. The board of directors is typically structured to have a variety of perspectives and expertise, although there are typically more people with business backgrounds involved as employees and board members (Papadimos et al. 2013). Community members participate in social enterprises as consumers of the products and services offered by the organization (Jackson and Harrison 2011). Therefore, social entrepreneurs must work to fill the gaps important to community members.

Regardless of the model, success relies on an organization's ability to take effective action and meet desired goals (Hawe et al. 2000). Healey suggests that such success can be secured with social infrastructure that is rich in "institutional capacity." Healey (1998:1541) defines institutional capacity as "encompassing intellectual capital (knowledge resources), social capital (relational resources), and political capital (mobilization potential)."Capacity requires more than simple know-how. It also requires the inclusion of diverse participants who can bring diverse perspectives to bear, effective organizational and leadership skills to encourage people to work together, the ability for participants to deliver on their commitments, and the foresight to take advantage of emerging opportunities. According to Healey (1998:1541), rich institutional capacity "allows rapid mobilization to new circumstances and enables flexible responses to be designed and developed." Her framework provides a mean to analyze both potential and practice of sustainability-oriented organizations. We suggest that organizations with high institutional capacity are typically better able to adapt to changes in external conditions, e.g., funding or policy fluctuations, without significant declines in the functional output of the organization. Both models potentially contribute to that capacity.

The stakeholder model is, in theory, effective at bringing different knowledge, expertise, and perspectives together to build trusting relationships and develop better-informed and robust decisions. A commonly cited drawback, in relation to institutional capacity, is the mobilization potential of the stakeholder model (Reed 2008). In the social entrepreneurship model, the knowledge and expertise focus less on diversity and integration, and more on relevance, applicability, and the ability of participants to mobilize action related to the organization's mission and goals. Organizations using a social entrepreneurship model are missiondriven and measure their success on their ability to realize their organizational goals; however, the relationship between the public and the organization must be robust, or else the organization will fail.

\section{CONTEXT AND RESEARCH METHODS}

$\mathrm{BRs}$ are UNESCO-designated regions and organizations that operate at the landscape level to carry out three functions: conserve biological and cultural diversity; advance sustainability; and support scientific research, learning, and public education (UNESCO 1996). Aiming to engage and empower communities, BRs emphasize citizen participation in conservation, research, development initiatives, and skills' training. Canadian BRs have historically been structured as multistakeholder forums designed to involve diverse participants such as municipal, provincial, and federal governments; representatives of natural resource industries (forestry, fisheries, mining, agriculture, ecotourism) and environmental organizations; academic and/or government researchers and "members-at-large." Many BRs have seats available for First Nations representatives, although as of 2014, active participation of First Nation groups was minimal across 
the BRs studied. Each BR has a different mechanism for identifying representatives. In some cases, board members may be prescribed by the BR's terms of reference. Municipal and Aboriginal leaders from the region are examples. Some resource sector representatives may also be appointed. In some cases, members are elected from the general public. Typically, these people have been actively involved in establishing the BR. Academic or scientific members of the board (who have often conducted research in the region) have become involved in this way. Frequently, BR boards have a combination of appointed and elected members (Francis 2004).

The Canadian federal government provided core funding from 2009-2012 through Environment Canada, which was used to support a local staff member (approx. CAD \$57,000/yr). In 2012, the federal government abruptly terminated its funding and the BR organizations once more had to rely on specific project grants and donations to fund their core operations. Today, Canadian BRs are seeking to diversify their funding sources to include earned revenue to adapt to increasing competition among nonprofits for a shrinking pool of available funding. In some cases, BR organizations are embracing the idea of social entrepreneurship as a mechanism to generate their own revenue in response to the changing landscape of public funding and private philanthropy. Through using a multiple-case study, we compared different BRs (Yin 2014). Most of the cases were located within a single broad region, the Canadian Maritimes, allowing us to focus attention on shared attributes and challenges. Manicouagan-Uapishka BR is outside of the region studied, but as a BR in a rural and remote region, it faces similar challenges and is governed under the same international program as the other BRs. The four cases presented here exemplify a continuum of practice, with the first having wholly adopted the stakeholder model and the last having adopted a social entrepreneurship model (Fig. 1). Classifications have been decided based on the governance and funding structure of the organization, the use of commercial activities, and the innovation shown in their ability to offer social or environmental value. We consider the first case, Southwest Nova, as a stakeholder model because its governance structure comprises a stakeholder board, it has relied solely on grant funding, has not explored commercial activities, and has, comparatively, few innovative outcomes. The last, ManicouaganUapishka (MUBR), is considered a model of social entrepreneurship because it has diversified its governance structure and revenue-generating strategies to include innovative business operations that have offered broad social and environmental benefit. Cases two and three have adopted attributes of each to varying degrees.

The four organizations differ from one another in a number of ways. First, the age of the organizations varies from 14 to 4 years at the time of analysis. Indeed the age of the organization affects its life-cycle stage, which may impact how the organization is governed, as well as its productivity (McClusky 2002). The BRs identified are located in three different Canadian provinces. All of these provinces have average incomes lower than the national average, as well as an average age higher than the national average. Each of the areas occupied by the BRs rely heavily on tourism and resource extraction. We should note that in Baie Comeau (the largest town in MUBR), the average household income is high in comparison to the other areas (Statistics Canada 2008).
Fig. 1. Biosphere reserves located in Atlantic Canada. The numbered circles (1-4) represent each of the biosphere reserves studied. Their geographic reach is represented in black.

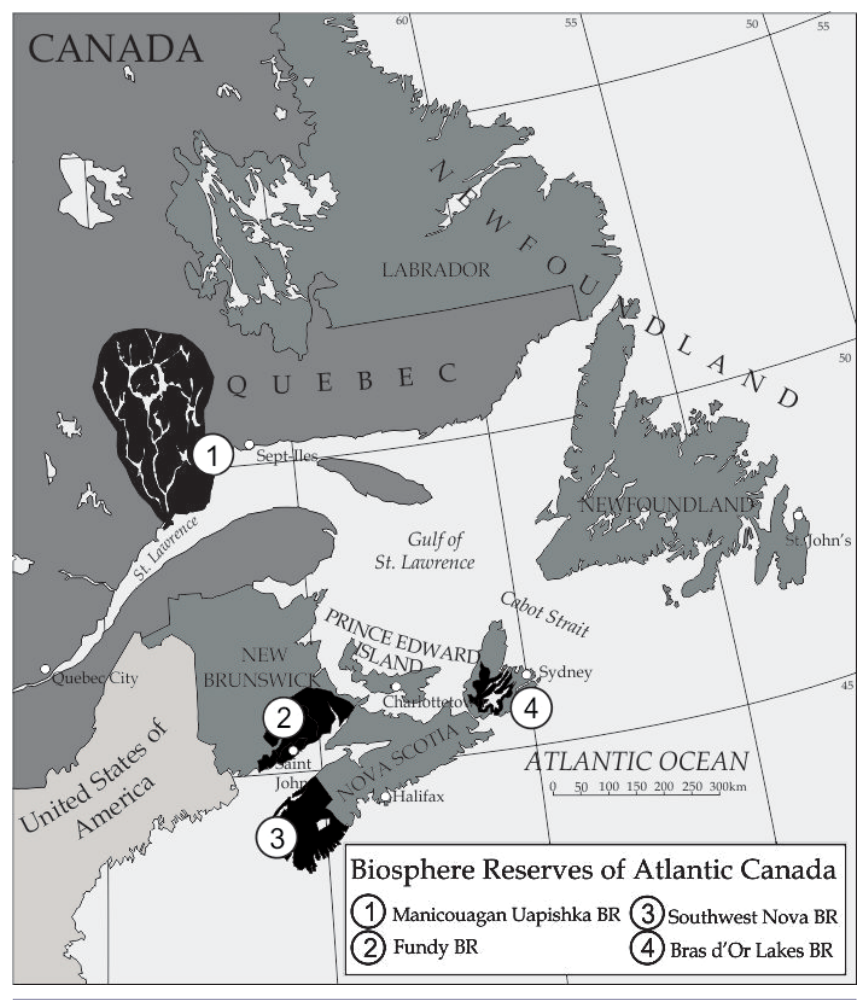

We examined how the governance of these organizations has impacted their ability to achieve their organizational goals and successfully adapt during periods of internal and external change. We did this using two methods: (1) We performed a document review of strategic planning documents, annual reports, newsletters, and information made available by the BRs operating in Atlantic Canada and Québec; (2) We conducted 23 in-depth interviews from 2011-2014 with members central to each of the organizations. Interviews were transcribed verbatim. Relevant documents and interviews were coded using qualitative analysis software, NVivo 10, to determine current governance priorities and organizational strategies, as well as the success of the organization to fill its mandate.

\section{APPLICATION OF THE MODELS IN CANADIAN BIOSPHERE RESERVES}

We present individually some of the history and challenges faced by the BRs. However, because of the small number of people involved who are likely to know one another, we opted to combine the cases when assessing institutional capacity in order to protect the confidentiality and integrity of the research participants and their organizations. A summary of the information provided is available in Table 1.

\section{Southwest Nova BR}

Southwest Nova BR was formally designated in 2001. Their BR association, SNBRA, functions using a policy governance stakeholder model, meaning that the board sets the strategic 
Table 1. Summary table of characteristics of the biosphere reserves (BRs) explored, including Southwest Nova Biosphere Reserve (SNBRA), Bras D’Or Lake Biosphere Reserve (BLBRA), Fundy Biosphere Reserve (FBR), and Manicouagan-Uapishka Biosphere Reserve (MUBR). 'BLBRA was established after Environment Canada money was allocated to the BRs and, therefore, never had federal funding. BRs also receive funding for summer students and short project contracts not included here.

\begin{tabular}{|c|c|c|c|c|}
\hline & SNBRA & BLBRA & FBR & MUBR \\
\hline Year Established & 2001 & 2011 & 2007 & 2007 \\
\hline Board Structure & $\begin{array}{l}\text { Representative stakeholder } \\
\text { model }\end{array}$ & $\begin{array}{l}\text { Representative stakeholder } \\
\text { model }\end{array}$ & $\begin{array}{l}\text { Representative stakeholder } \\
\text { model }\end{array}$ & $\begin{array}{l}\text { Board appointed based on } \\
\text { values and expertise }\end{array}$ \\
\hline Board Size & 21 members & 20 members & 16 members & 9 members \\
\hline Staff 2011 & 1 Manager & No paid staff ${ }^{\dagger}$ & $\begin{array}{l}1 \text { Executive Director } \\
1 \text { Conservation Program } \\
\text { Manager (PT) }\end{array}$ & $\begin{array}{l}1 \text { General Director } \\
1 \text { Project Manager and } \\
\text { Communications Coordinator }\end{array}$ \\
\hline Staff 2015 & No paid staff & No paid staff & $\begin{array}{l}1 \text { Executive Director } \\
1 \text { Conservation Program } \\
\text { Manager (PT) } \\
1 \text { Communications Director } \\
\text { (PT) }\end{array}$ & $\begin{array}{l}1 \text { General Director } \\
1 \text { Project Manager and } \\
\text { Communications Coordinator } \\
1 \text { Senior Advisor, Sustainable } \\
\text { Development and Territorial } \\
\text { Organization } \\
1 \text { Accounting Manager (PT) } \\
1 \text { Secretary (PT) }\end{array}$ \\
\hline $\begin{array}{l}\text { Decision-Making } \\
\text { Strategy }\end{array}$ & $\begin{array}{l}\text { Decisions go to the board } \\
\text { and are debated. }\end{array}$ & $\begin{array}{l}\text { Chair and individuals } \\
\text { working on specific projects } \\
\text { make relevant decisions. The } \\
\text { Board is informed of } \\
\text { progress and can offer } \\
\text { feedback. }\end{array}$ & $\begin{array}{l}\text { Executive Director takes } \\
\text { advantage of opportunities. } \\
\text { The Chair is in contact and } \\
\text { the Board is informed and } \\
\text { can offer feedback. }\end{array}$ & $\begin{array}{l}\text { Board is responsible for the } \\
\text { direction of the BR. } \\
\text { Decisions are brought to the } \\
\text { board. A multistakeholder } \\
\text { Orientation Table offers } \\
\text { advice and guidance to the } \\
\text { BR biannually. }\end{array}$ \\
\hline Characteristics & $\begin{array}{l}\text { Passive board; } \\
\text { Diverse expertise; } \\
\text { Difficult to find new } \\
\text { volunteers; } \\
\text { Desire to increase output } \\
\text { and communications. }\end{array}$ & $\begin{array}{l}\text { Difficult to mobilize } \\
\text { volunteers; } \\
\text { Need financial support; } \\
\text { Strong network; } \\
\text { Desire to increase output; } \\
\text { Diverse expertise. }\end{array}$ & $\begin{array}{l}\text { Flexibility to take on } \\
\text { projects; } \\
\text { Working with many partners } \\
\text { (strong network); } \\
\text { Diverse expertise; } \\
\text { Raising profile through } \\
\text { projects; } \\
\text { Challenged to maintain } \\
\text { mandate. }\end{array}$ & $\begin{array}{l}\text { Developed a community } \\
\text { vision for sustainability; } \\
\text { Maintain a strong network; } \\
\text { Raising profile through } \\
\text { initiatives. }\end{array}$ \\
\hline
\end{tabular}

direction for the BR and makes the final decisions regarding operations and management, including projects, funding, and other governance activities. The board has a maximum of 21 members including representation from what they call three sectors: industry/development, government/First Nations, and nongovernment. The BR has a core group of committed members who have participated since the beginning. One interviewee explained:

\section{I guess the original board members that have stayed with the biosphere reserve since it began stick with it because they have an intrinsic interest in the biosphere reserve concept and want it to succeed in Southwest Nova. These are the members who speak publicly about the biosphere reserve and champion the concept.}

Despite the benefits of stakeholder model and the commitment of those who champion the concept, SNBRA has been challenged in several ways. The large geographic size of the BR (covering an area of $1,546,374 \mathrm{ha}$ ), as well as the depressed economy in southern Nova Scotia has made it difficult for the association to muster the capacity and resources to move forward with its mandate. One board member explained this challenge this way:
I mean, we looked at the area of the biosphere reserve and said, "Woah, this is a big piece of geography." We are going to be overwhelmed if we have to deal with what is going on in all of the five counties (that are part of the area of the biosphere reserve).

Because of the size of the area, and the limited capacity within the organization, interviewees expressed that it has been difficult for SNBRA to achieve a presence in the communities that are part of the BR. Internally, there are challenges as well. Along with the other BRs, in 2009, SNBRA received funds from the federal government department, Environment Canada, which paid for a staff member. Participants reported that this funding changed the dynamic of the organization. One interviewee said the following:

In general, the funding for staff has been a detriment to the board. Because the permanent staff are charged with doing the work of the biosphere reserve, the board has become more passive. Because board members think that there is someone hired to do the job, they don't participate actively in the biosphere reserve.

Staff changes followed by funding cuts in 2012 further limited the capacity of the organization. All interview participants from 
SNBRA expressed their desire to increase project output, encourage community participation, and improve the profile of the BR. Despite this desire, most board members interviewed were uneasy about moving away from their current governance model to embrace more entrepreneurial attitudes, echoing fears described in the BR's strategic planning documents (i.e., SNBRA 2010).

\section{Bras d'Or Lake BR}

Bras d'Or Lake BR, founded in 2011, never received federal funding. The Bras d'Or Lake BR Association (BLBRA) operates through a 20-member voluntary board of directors with representation from the various geographic locations around the lake, the municipal and First Nations governments, and other volunteer organizations involved in lake-related projects. BLBRA has worked successfully with existing organizations to determine their role on Cape Breton Island and have successfully partnered with other organizations and expertise in the region to move projects forward. The group worked tirelessly for years to achieve designation, but once the BR was formally designated, the group had difficulty maintaining momentum. One interviewee expressed this as follows:

\section{The biggest challenge is there aren't enough people doing enough of the work that could be done for the biosphere reserve. It could be that I'm just frustrated and expecting that more would have happened by now than is happening; ... I feel as though more could be being done.}

Despite challenges, the BR has advanced a few projects including an inventory of all of the organizations within the watershed to determine complementary capacity, signage to increase public awareness of the BR, curriculum development for Grade Four science students, and online resources to educate the public about the BR. Although BLBRA has support from diverse expertise, cultural backgrounds, demographics, and organizations, including all levels of government and First Nations communities, interviewees expressed concern about their ability to move forward because of the lack of financial capital, reliance on volunteers, and the lack of broader knowledge of and support for the BR.

The BLBRA has volunteers and a strong network of organizations willing to participate with the BR. However, interviewees disclosed that, without a central person managing the projects and the associated human capital, the Association has not identified a suitable way to mobilize action with these groups.

\section{Fundy BR}

Established in 2007, Fundy BR (FBR) had government funding for most of its existence. FBR's board includes 16 representatives from academic institutions, conservation and heritage organizations, government and municipalities, First Nations, community development agencies, and resource and tourism sectors. The board allows the staff the flexibility to take advantage of opportunities that the staff feels fit within their broad mandate. One interviewee responded to a question by saying the following:

You mentioned something about innovation in our projects.... we're pretty good at jumping on opportunities when we see them. My board doesn't micromanage me so I don't ask many questions if an initiative fits generally within our mandate and or strategic plan then I go.
FBR has been successful in receiving grants from various government initiatives, as well as private granting opportunities for a variety of projects; however, the BR has not yet used commercial activities for revenue generation. Staff and board members continue to be mobilized because of their proactive and enthusiastic attitudes. One interviewee stated the following:

\begin{abstract}
We take a very proactive approach and the staff that we have on board are also like that and we work well together to get the message out and lead by example.
\end{abstract}

This claim is founded, in part, by a desire to "create a cooperative network of partners who will work to assist communities to achieve greater sustainable development" (FBR 2015). To this end, it has partnered with educational institutions, the private sector, Parks Canada, cities and municipalities to complete all of its major projects and build a stronger network. One interviewee described FBR's collaboration on the Trans Canada Trail Project:

\begin{abstract}
The trail project... is a great example of how partnerships work: You find an organization that is like-minded and you take a risk and you think outside the box, which the Trans Canada Trail was. Essentially, in order to get this project built we had to map the assets. I got [financial support ]... from $M E C^{[1]}$,... from Loblaw Corporation and Trans Canada Trail, ... from a local community development agency,... from health, wellness and sport, and the sky is the limit with this project. With all of this support, it expanded from a trail project to an environmental education and stewardship project.
\end{abstract}

Until 2012, the Executive Director was paid from funds provided by Environment Canada. Additionally, a few part-time and seasonal staff members were funded through grants awarded by the provincial and federal governments. When federal funds were cut, FBR was able to maintain its staff because of its continued success finding project funding. However, a financial plan that relied primarily on project funding made it challenging to address the broader mission and strategic plan of the BR. As one interviewee explained, "since the funding cuts, we can't be too picky. We can't afford to be picky."

Relying only on project funding meant that engaging with new partners was difficult; project grants did not pay for the time needed to foster new and existing relationships. For example, FBR started a Charter Membership Program to raise awareness of, and help engage the local community in, sustainability initiatives. However, without core funding, staff members could not allocate time to making the program more meaningful for those involved. Financial pressure caused the organization to deviate from their strategic goals. Previous to the funding cuts, public education, outreach, and communication were identified as key priorities for the organization; however, as FBR found very few project grants available in these areas, interviewees were not optimistic about the organization's ability to meet these priorities.

Following the federal funding cuts, the FBR started looking into revenue-generating options to support the economic sustainability of their organization. In keeping with social enterprise, they looked into individual donations through PayPal, as well as selling their services through a for-profit arm that marketed the expertise found within their organization to fund their nonprofit work. One interviewee explains the challenges associated with transitioning to social entrepreneurship: 
I know one or two other organizations that do it and it works pretty well. It takes an investment of capital. This would probably be the problem. For example for GIS services, if we were going to go that route, we would have to purchase a license and that's expensive. We would also have to consider what our expertise is.

This observation suggests that a shift toward social enterprise is not seamless, requiring strategic planning and a keen sense of what the broader community requires.

\section{Manicouagan-Uapishka BR}

Manicouagan-Uapishka BR (MUBR) was also designated in 2007. At that time, the MUBR adopted the traditional stakeholder model and sought funding by competing for grants. Four specific issues prompted managers of the BR to adopt a social entrepreneurship model in 2009. First, as the organization grew and began to partner with more organizations, those partner organizations wanted to hold a position on the board. However, as an interviewee describes below, increasing the number of seats on the board was not realistic:

When we were operating under the stakeholder model we had 15 board members. It is difficult to operate with 15 board members... but the thing was that they were all representing a partner and because we were partnering with more and more organizations there were more and more organizations wanting to be a part of the board. This was because the board was the only place that you could be a part of the biosphere reserve. So we had a problem there. And everyone thought that we would increase the number of board members when in fact, we did the opposite - we reduced it to 9.

The governance structure of MUBR is different than other BRs in Canada. Rather than having seats dedicated to specific categories of stakeholders, new board members are selected for their personal knowledge and expertise, their availability and willingness to be involved, and their motivation to contribute. The BR seeks board members with a combination of entrepreneurial skills and experience, influence and connections in the region, as well as social and environmental values that complement the BR's vision and mission. Under this new vision, interviewees reported that the board is more comfortable with a certain amount of financial risk. One interviewee explained:

We decided to have nine people who are actually there for who they are, not the organization that they are representing... because of their own skills and interests. When we reduced the size of the board we wanted to get people who were more in line with the outcomes of the strategic planning exercise and the organizational objectives.

In addition to the Board, there is also an Orientation Table, which serves as a multistakeholder advisory committee. One interviewee described the structure and the formation:

We created the orientation table.... Everyone who wanted to deal with strategic planning and project orientation could go there and everyone who wanted to deal with the administration of the organization (salaries, the day-today) would come to the board. It wasn't tough at all. Many of our partners were much more interested in the orientation table than doing the more administrative work. The orientation table has no quorum. The division happened very naturally.

The Orientation Table offers an opportunity for partners to participate in the BR. It also serves as an accountability structure to community partners and helps to address the possibility of mission drift, a situation where financial goals, rather than the social mission, begin to dominate and drive organizational changes (Bielefeld 2009). The second issue that prompted the adoption of a social entrepreneurship model was that members of the BR sensed that the political climate was very volatile and members did not want to rely on government funding for their organizational sustainability. The two interview quotes below describe the context:

We had to adapt to the context. Politically, we had a conservative government in at the federal level and a liberal government in place at the provincial level and, together, those two governments killed the grant programs. So the size of the cake that we as an NGO could share was getting smaller and smaller and it was getting tougher and tougher to receive grants. And we could see it was only going to get worse.

We said if we do not create something that we would be able to sell, if we do not create expertise that we will be able to sell, we will just sink. And this is exactly what would have happened in 2012... We would have crashed like a few other biosphere reserves crashed across the country.

The third issue was the challenge of meeting their organizational mission through the financial constraints of project funding. One interviewee explains:

Grants decide the objectives. I think lots of NGOs twist their projects to fit the criteria of the grant and you have to do your project in a way that the grant provider will be happy with. [Also,] grants will never pay salaries... You can buy a shovel, you can rent a pickup, but you can't pay anybody. So you're screwed.

The fourth motivation was the need to refine their mission and mandate to better fit the needs of the communities they work with and find a mechanism to connect more effectively with their community to promote sustainability. MUBR identified the social entrepreneurship model as a strategy for improving their financial viability while offering products and services that more effectively engage the community to work toward sustainability.

Following a strategic planning session in 2010, MUBR began to offer sustainability services to surrounding communities. They began working toward developing recognized expertise in this area and started to consult with the private sector, helping private companies (e.g., Alcoa) and municipalities (e.g., Baie Comeau) design sustainability plans. The quotes below describe MUBR's plan:

We started this process to put in place a sustainability vision. And the only way we can do that is to help the partners themselves with their sustainability plan. The broader vision of sustainability will need to come from them. And what we're doing is walking with them towards this objective. 


\begin{abstract}
We did not start to provide sustainability services because it was a gap in the market. It's because it's our mission. We found a very original and economical way to fulfill our mission. .... The money that we generate through this is used to fund the other parts of our organization, including our work on education and First Nations projects.
\end{abstract}

MUBR recognized the limitations of this funding structure, identifying that the BR must work for people who can pay. They prioritized working with the municipality because the rural areas do not have the capacity to pay their consultation fees. MUBR has continued to apply for funding and grants, but this money becomes an addition to the overall organizational budget, rather than the main source of funding.

\section{ASSESSING INSTITUTIONAL CAPACITY IN THE BIOSPHERE RESERVES}

The capacity of the BRs to access the three primary resources of institutional capacity is described below. Because the organizations are small and residents live in small communities, results are presented together so as to ensure the confidentiality of interviewees and specific biosphere reserves.

\section{Knowledge resources and expertise}

Support for multistakeholder participation in the BRs was affirmed by every interviewee; however, representatives from the three Atlantic BRs identified a need for knowledge and expertise to extend beyond the stakeholder model in four ways. First, they stated that the knowledge and expertise represented on the board of directors for BRs overemphasizes certain knowledge, perspectives, and expertise, making other opinions and perspectives underrepresented. For example, one interviewee described their board of directors as "a bit too lopsided, towards government and research, and not a realistic representation of what the community is made up of."

Second, a need for expertise in areas including marketing, finance, fundraising, public relations, and economic development was identified, as described in the following quotations: "I think that we need to get more private sector people on the board - just their way of thinking and their experience doing business;" "I'm not a marketing person per se, and I would love to have help from somebody who actually knows how to create that stuff."

Third, although seats may be filled on the board, it was suggested that the knowledge and expertise that is brought to the table is not employed to advance the mission of the BR. One interviewee explained:

\section{I think there are a lot of knowledgeable people in the group that bring expertise to the table, but they need to be tapped-whether it's a municipal counsellor who could talk about how he works with his constituency, or a scientist, or a forest management person ... There is tonnes of expertise there [on the board] and I don't think that they're [the board members] being tapped to their potential.}

And, finally, participants identified a need to find people with a passion for the organization's mission and values, rather than those who are seen as holding an identified stake. One interviewee expressed the need for people to move things forward:
I feel that there should be more doers: those who are engaged and keen to do things. And part of it's the board structure. We have a lot of people on our current board and it has people there because of who they represent, as opposed to because they're keen on the biosphere reserve.

Interviewees at MUBR recognized the importance of having diverse perspectives, but they indicated the need to have specific knowledge and skills within the organization to fulfill mission objectives and to obtain those skills, where necessary. Interviewees described how they built the skills within their organization: "We needed to go get the skills. We attended training sessions. We got together with people who had the skills."

\section{I would say that the other skill is to be using tools. When we were looking at other organizations that were doing this type of work ... they were using mind maps, graphing software and prioritization models. It is important to have these tools. When you arrive in front of business people and say we're going to do it on the screen and actually show them they say, "Oh, this actually works." So we've been developing tools to have preformatted action plans and we're always seeking new ways to achieve good results.}

The knowledge and expertise on MUBR's board, therefore, is focused on contributing to the organization's outputs, as opposed to solely having diverse knowledge and expertise. This diversity is reflected at their Orientation Table.

\section{Relational resources}

Representatives interviewed from all BRs emphasized the importance of building strong social networks and connections with their partners, the communities, as well as those with broader power and decision-making abilities. Although participants from each BR expressed this desire, the Maritime BRs reported that local communities are relatively unaware of BRs. One interviewee explained: "I think that within the community we are mostly unknown. I don't think the community thinks that we do anything. They don't know what we do and they don't think we do anything."

Without significant financial or human capital, BRs are unable to establish and maintain networks and build relationships with identified stakeholders or potential partners. Even in FBR, an organization that has been comparatively successful at building partnerships and fostering active engagement, relational resources are challenged by funding directives. One interviewee explained that outreach is "harder because we're very project oriented. It's harder to get money for." As mentioned above, FBR has had to deprioritize their Charter Membership Program, an initiative that promotes community participation in sustainability, in favor of initiatives that are more financially viable.

Although FBR's board participation has remained strong, SNBRA and BLBRA have experienced a drop in board participation. Members of their organizations described this as follows: "We couldn't get quorum, official quorum, which is $50 \%$ of our board members... all of last year, for any meeting last year."

[Board] attendance has dropped off in many cases. For the AGM this week, ... seven have responded saying that they are attending... I think people are stretched thin and they cannot commit the time to come explore an abstract concept like the biosphere reserve. 
Another issue reported by all organizations was the challenge between collaborating with other organizations and competing with them for grants. One interviewee explained:

There are a lot of NGOs... that have a conservation orientation and there's a lot of competition for money... We haven't really staked out what we should be doing and therefore someone else is stepping in and saying, "We'll take the money, we will do that."

MUBR reported using social entrepreneurship to help mitigate these challenges. As the quote below describes, by employing a social entrepreneurship model, MUBR found that initiatives have become more community focused and, consequently, community participation has increased.

So we aren't only thinking of applying our UNESCO mission, we are trying to apply it in a way that will be useful to our partners... Before we mostly said to partners, "We are a UNESCO biosphere reserve. We have this mandate and you should support us to do it. You can support us with a letter of support or provide us with a grant." But we were never useful to that grant provider. Now it is completely different.

When asked whether public participation has decreased at MUBR as a result of shifting to a more entrepreneurial model, one interviewee responded:

I'd say not at all. In fact, it has increased. Much of our work is with municipalities and our bigger mandate working on the Ma Ville, Ma Voix ${ }^{[2]}$ project and we're organizing three forums every year. ... I would say that since doing this we have more capacity, a greater ability to leverage [funding, resources] because we are dealing directly with the partners.

When MUBR shifted from the stakeholder model to a more entrepreneurial approach, relationships strengthened and public participation increased.

\section{Mobilization potential}

Of the three elements of institutional capacity, mobilization potential poses the greatest challenge for BRs using the stakeholder model. BRs operating under the stakeholder model identified four key constraints to mobilization. First, they reported that, although the breadth of the UNESCO-mandated biosphere functions of conservation, capacity building, and sustainable development allowed for flexibility for local implementation, it sometimes became overwhelming and stagnating because they offer no operational or strategic direction. This was particularly true for SNBRA, with several interview respondents identifying this challenge. Consequently, board members tended to adopt a "wait and see" approach rather than make implementation decisions. Second, BRs with lower organizational capacity reported becoming increasingly disconnected from the geographic and social communities where they operate. They attributed this disconnection to their lack of community profile and limited community engagement. All BRs emphasized the need to improve their communication and outreach capabilities; however, this goal had proved difficult under the stakeholder model because there was no funding available that focused strictly on these outcomes. MUBR has been able to hire a communications coordinator. FBR has also had paid staff to serve in this capacity. Third, the large number of board members had generated, over time, people with entrenched positions. Because of the difficulty engaging new membership, it was difficult for some organizations to maintain momentum as some partners had left, and those who remained stagnated. One interviewee explained the situation in their organization as follows:

I do think that there are directors who have sat on the board for years and because they're just not getting anything out of it and they're not contributing anything, they decide to leave. There needs to be a push towards a more active board. Volunteers can do a lot and will do it well, as long as they know that what they do is going to be used and useful.

Having a governance structure that supports various forms of participation, like that practiced in MUBR, may be a way to help foster board turnover, as those involved in the biosphere reserve are able to choose how they participate in the organization. These three factors contributed to a fourth challenge: mission drift and stagnation. Where initiatives were taken, they often involved pursuing project funding that lay outside of the original strategic agenda of the BR. Mission drift was also expressed by MUBR as a challenge associated with the social entrepreneurship model. One interviewee explained this as follows:

I would say that we're investing far more energy in the
lucrative [activity], which is very important. We are still
doing stuff with the others [applying for project grants];
we have the annual reports to prove it. But of course, first
because it's more lucrative, and second because when you
enter into a business relationship you start to work and
you need to provide results so you take care of it and it
becomes a priority. When you deal with trying to put
together pride in the region, a feeling of belonging, these
are long-term objectives that, daily, you won't get a phone
call from anyone about reminding you that you need to
increase the feeling of pride in the region, but you will
get a call from a client. So it does create a little bit of an
imbalance in the priorities.

It appears that mission drift is a significant factor regardless of the model adopted by the sustainability organization. In organizations pursuing funding through project-based grants, their organizational priorities are shaped by available funding calls. Using a social entrepreneurship model, MUBR also found they were prioritizing projects that were client funded. This influenced organizational outcomes related to their mission.

\section{DISCUSSION: INTRODUCING ENTREPRENEURSHIP TO SUSTAINABILITY ORGANIZATIONS}

The BRs involved in this study identified several challenges associated with operating under a stakeholder model. However, transitioning completely from the multistakeholder model to embrace a social entrepreneurship model may also be undesirable because certain characteristics emphasized by the stakeholder model including broad participation, diverse perspectives, knowledge sharing, deliberative practice, and collaboration may become undervalued in a model that focuses strictly on social entrepreneurship. Our analysis shows that MUBR has actually 
adopted a social entrepreneurship model that offers characteristics of both the social entrepreneurship and the multistakeholder model: a targeted, small, and active board, and a larger, advisory multistakeholder Orientation Table. This Orientation Table allows the organization to take advantage of the benefits of a multistakeholder arrangement. Although this model fits within the understanding of social entrepreneurship, we draw attention to the complementary capacity built into MUBR's governance model by relabeling it as the social entrepreneurship/multistakeholder hybrid model, referred to as the hybrid model (Fig. 2). To date, none of the 16 Canadian BRs has adopted a model that does not incorporate a multistakeholder component. A multistakeholder accountability mechanism may help ensure the organization operating as a social enterprise does not experience mission drift, a common concern discussed in the social entrepreneurship literature. Our results suggest that to avoid stagnation, BRs operating under a stakeholder model can achieve complementary capacity by incorporating elements of social entrepreneurship into their institutional structure. From our analysis, there are four key ways incorporating a more entrepreneurial approach will enhance institutional capacity.

Fig. 2. Stakeholder model vs. hybrid model in the biosphere reserves explored. Although most biosphere reserves operate using a version of the stakeholder model (a multistakeholder board with selected representatives serving as the board executive and, if financially feasible, one or two staff members), Manicouagan Uapishka Biosphere Reserve uses a hybrid model that incorporates characteristics of both the stakeholder model and the social entrepreneurship model. This allows the organization to have diverse representation through their advisory committee, while having an engaged and active board with the knowledge and skills necessary to work with staff members to move the organization forward.

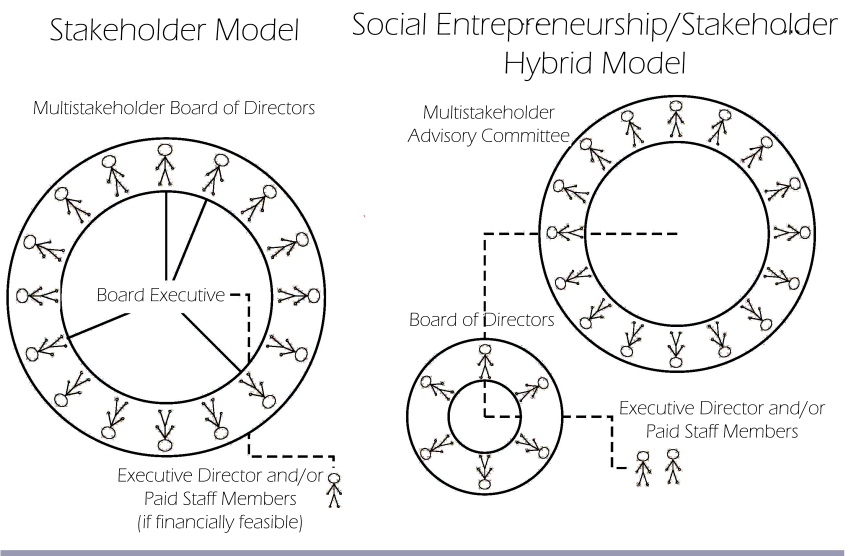

\section{Targeting expertise and values}

As Healey (1998) indicated, the success of an organization or initiative requires more than diverse knowledge and expertise and relational resources; successful mobilization requires engaging those capable of moving things forward. Healey (1998) emphasized the importance of political capabilities in maximizing mobilization potential, while Lockwood et al. (2009) suggested that the efficacy of managers, boards, and organizations is imperative to achieve institutional success. Social entrepreneurship models draw attention to the need to expand understandings of mobilization potential beyond considerations of political efficacy and influence. Although important, mobilization requires more than political capital. The cases examined here reveal the importance of recruiting members who have the knowledge and expertise to fill the logistical functions of the organization, specifically skills in business and management, as well as have the entrepreneurial attitude to drive strategic action. Our findings suggest that targeting the right people, who are not necessarily "representative stakeholders," who have appropriate interests, expertise, and drive will help the organization operate successfully. Such was the experience in MUBR. While not following that model, the other BR interviewees confirmed this requirement when they expressed a need for board members with expertise in marketing, fundraising, communications, and economic development to help them with day-to-day operations.

\section{Promoting diverse opportunities for stakeholder and community engagement}

The strategies used to encourage participation greatly shape who participates, as well as how individuals and groups participate in the decisions and initiatives that grow out of the process (Reed and Davidson 2011). The stakeholder model supports the inclusion of a diversity of actors to receive input from multiple sources; however, it is important that participatory structures are effectively designed to promote active contributions and meaningful engagement. There is a tendency for stakeholder boards to become idle because the model emphasizes the importance of dialogue, discussion, and consensus, as opposed to productivity and outcomes (Singleton 2002). This type of governance strategy does not encourage board members to be active. In the cases we examined, it resulted in near stagnation, characterized by frustration among board members about the lack of productivity within the organization, dropping attendance and board membership, poor levels of engagement and participation from those involved in the organization, and a general lack of public knowledge about the organization. Although some researchers have argued that broad knowledge, expertise, and perspectives results in more legitimate and robust environmental decisions (e.g., Reed et al. 2006, Reed 2008), others criticize this model for inhibiting timely decisions and decisive actions (e.g., Parkins and Davidson 2008). Our research suggests that both may be true. In the absence of a clear guiding strategic vision, consensus may simply mask indecision and inaction. By contrast, the model of MUBR involving a small action-oriented board and a multistakeholder advisory committee (their Orientation Table) offered two different ways to participate. By offering a hybrid model, MUBR encouraged meaningful and purposeful engagement of stakeholder groups and set clear objectives for the participatory process, thus encouraging members to show up ready to actively participate in either higher order strategic discussions or more immediate operational decisions. This model may also address issues of entrenchment in the stakeholder model because participants are able to select how they participate in the organization. Those appointed to the Board have a unique and active role. Board members may step back from a central role in the organization, but continue to participate through being a member on the Orientation Table.

\section{Encouraging strategic direction and associated outcomes}

Collaborative and participatory models of environmental governance move to advance a shared understanding of complex 
societal challenges (Healey 1998). Researchers and practitioners have suggested governance principles must ensure high level policy directives (such as the UNESCO mandate for BRs) are combined with the ideas and values of local stakeholders, appropriately synthesized, and expressed as a shared vision (Dale and Newman 2007, Lockwood et al. 2009). The shared vision must be comprehensive enough to account for diverse stakeholder perspectives, but directive enough to promote the development of strategic goals and attainable objectives (Healey 1998, Mitchell 2002). As part of the UNESCO Man and the Biosphere program, each BR is offered the same broad, high-level mandate to tailor to their specific context. However, we found those operating within a stakeholder model have had difficulty translating this mandate into a strategic direction and actions that suit their context. Adopting an outcome-oriented approach through social entrepreneurship became a way for at least one Canadian BR to ensure their organization continued to move forward effectively and had a set of targets against which to evaluate their outcomes. In doing so, adopting a social entrepreneurship model strengthened the mobilization potential of the organization and, thus, its institutional capacity. Other cases verify our findings, showing that implementing a social entrepreneurship model prompts participants to reframe their perspectives and adopt a vision for the organization that promotes more strategic action (e.g., Biggs et al. 2010).

\section{Offering opportunities for more diversified and stable funding models}

The BRs investigated identified a number of ways operating through project grants challenged their organization. First, project money is typically not well tailored to an organization's mission; hence, the mission may shift according to the funding source. Second, grants and other forms of funding opportunities typically do not compensate for administrative time, so in organizations where there is no core or foundational funding source, it is extremely difficult to run an organization strictly from project grants. Third, grant funding raises the collaboration/ competition conundrum as like-minded organizations typically compete for the same project funding. Civil society organizations have the opportunity to cooperate, pool resources, and share information, but because of the competition for funds, many nongovernment organizations are placed in a difficult position; organizations may undermine competitors, conceal information, and choose to act alone. For example, a national partnership for BRs suggested that, at the outset, some participants were reluctant to share their best practices with others, with concerns that this may give other practitioners a competitive advantage for funding (Reed et al. 2014). This concern was voiced by participants from all BRs examined when discussing grant funding. This competitiveness weakens many organizations, and also creates duplication, waste, and incompatible goals. It also weakens the unity and impact of collective outcomes. Finally, relying on project money is inherently unsustainable. An organization is unable to plan for the long term or build on their organization when they are operating through project grants. Adopting a strategy of diversified funding that includes social enterprise, as done in MUBR, promotes financial sustainability and allows the organization to build toward longer term goals. The diversified funding model also helps to ward against mission drift because it offers the potential for organizations to be more selective about funding opportunities, allowing them to choose initiatives that most align with their organizational mission.

\section{CONCLUSION}

We assessed the conceptual and operational feasibility of integrating social entrepreneurship into governance models emphasizing the importance of participation and collaboration. Review of the literature revealed that, conceptually, integration of the stakeholder and the social entrepreneurship models is indeed possible and could result in greater institutional capacity through drawing on the knowledge and expertise brought by the stakeholder model and the stronger mobilization potential of the social entrepreneurship model. Analysis of four BRs in Atlantic Canada and Québec revealed that organizations operating under the traditional multistakeholder model were less productive, less likely to meet their mission objectives, and more likely to experience crippling economic stress than those that incorporated entrepreneurial strategies. Interestingly, there were no significant trade-offs to date associated with the transition toward social enterprise at MUBR. Adopting key elements of a social entrepreneurship model at MUBR enhanced broad participation and collaboration and improved the organization's institutional capacity.

Whether this model can be maintained and readily transferred to other BRs and sustainability organizations more broadly remains to be seen because local contexts differ. MUBR is a new BR and its restructuring did not threaten entrenched interests. Additionally, while MUBR shares common features of Canadian rural life, such as depopulation of the youth, there are also significant local players willing to pay for services they provide, e.g., Municipality of Baie Comeau, Alcoa. In the more depressed economy of Atlantic Canada, such willingness may not be as forthcoming. Hence, we suggest turning to a hybrid that draws on the strengths of both. A hybrid that incorporates targeted participation, diverse opportunities for community engagement, strategic outcomes, and a varied funding model could help sustainability organizations shift from an inherently reactive situation to one that is more anticipatory and innovative. A hybrid will also help these organizations build effective partnerships with others to better address regional governance for sustainability. In this way, sustainability organizations may simultaneously build their institutional capacity while directly responding to community needs, thereby enhancing their sustainability mission.

Our focus on understanding and improving institutional capacity and collaboration through social entrepreneurship remains underexplored by environmental scholars. To date, such scholarship has focused more on critiquing existing arrangements than on offering alternatives. Our alternative combines the best features of two models. Because there is no BR organization that has fully adopted social entrepreneurship, and any new initiative will take a few years to take hold, it is not presently possible to determine whether becoming a social enterprise is a desirable option for BRs. Future research might more fully explore the spectrum of possible governance options by comparing a hybrid option against a strict social enterprise, should one emerge within the spectrum of organizations studied. Our research has revealed, however, that if sustainability organizations truly seek to make transformational change, they will need to develop new tools and 
improve ways of thinking. Research that thinks "outside the box" by targeting new kinds of strategies and identifying the means to make transitions will offer new options for sustainability organizations and will improve our understanding of the contribution of social innovation to advancing sustainability.

${ }^{[1]}$ Mountain Equipment Co-op is a Canadian member-owned cooperative specializing in outdoor and recreational sports equipment and ethical business practices.

${ }^{[2]}$ Ma Ville, Ma Voix (My City, My Voice) is a municipal initiative in the City of Baie Comeau to create citizen dialogue and develop a plan for sustainable development in the region.

Responses to this article can be read online at: http://www.ecologyandsociety.org/issues/responses. php/8229

\section{Acknowledgments:}

This research would not have been possible without funding from the Social Sciences and Humanities Research Council of Canada. We thankfully acknowledge the staff, board members, and partners of the biosphere reserves who participated in this work.

\section{LITERATURE CITED}

Bielefeld, W. 2009. Issues in social enterprise and social entrepreneurship. Journal of Public Affairs Education 15 (1):69-86.

Biggs, R., F. R. Westley, and S. R. Carpenter. 2010. Navigating the back loop: fostering social innovation and transformation in ecosystem management. Ecology and Society 15(2):9. [online] URL: http://www.ecologyandsociety.org/vol15/iss2/art9

Cropper, M. L., and W. E. Oates. 1992. Environmental economics: a survey. Journal of Economic Literature 30(2):675-740.

Dale, A., and L. Newman. 2007. Governance for integrated resource management. Pages 56-71 in K. S. Hanna and D. S. Slocombe, editors. Integrated resource and environmental management: concepts and practice. Oxford University Press, Toronto, Ontario, Canada.

Francis, G. 2004. Biosphere reserves in Canada: ideals and some experience. Environments: A Journal of Interdisciplinary Studies $32(3): 3-26$.

Freeman, R. E. 2010. Strategic management: a stakeholder approach. Cambridge University Press, Cambridge, UK. http:// dx.doi.org/10.1017/cbo9781139192675

Fundy Biosphere Reserve(FBR). 2015. Annual Report 2014-2015. FBR, Moncton, New Brunswick, Canada.

Granados, M. L., V. Hlupic, E. Coakes, and S. Mohamed. 2011. Social enterprise and social entrepreneurship research and theory: a bibliometric analysis from 1991 to 2010. Social Enterprise Journal 7(3):198-218. http://dx.doi.org/10.1108/17508611111182368
Hawe, P., L. King, M. Noort, C. Jordens, and B. Lloyd. 2000. Indicators to help with capacity building in health promotion. Australian Centre for Health Promotion/NSW Health, Sydney, Australia.

Healey, P. 1998. Building institutional capacity through collaborative approaches to urban planning. Environment and Planning A 30(9):1531-1546. http://dx.doi.org/10.1068/a301531

Jackson, S., and G. Harrison. 2011. Social entrepreneurship: concepts and implications for problem solving. Pages 1-24 in D. Sampson, editor. Social entrepreneurship: business issues, competition and entrepreneurship. Nova Science, New York, New York, USA.

Kerlin, J. A. 2013. The 501(c)(3) Nonprofit social enterprise. Pages 27-46 in T. S. Lyons, editor. Socialentrepreneurship: how businesses can transform society (Vol. 1). Praeger, Santa Barbara, California, USA.

Lockwood, M., J. Davidson, A. Curtis, E. Stratford, and R. Griffith. 2009. Multi-level environmental governance: lessons from Australian natural resource management. Australian Geographer 40:169-186. http://dx.doi.org/10.1080/00049180902964926

McClusky, J. E. 2002. Re-thinking nonprofit organization governance: implications for management and leadership. International Journal of Public Administration 25(4):539-559. http://dx.doi.org/10.1081/pad-120013255

Mitchell, B. 2002. Resource and environmental management. Second edition. Pearson Education, Harlow, UK.

Nicholls, A., editor. 2006. Social entrepreneurship: new models of sustainable social change. Oxford University Press, New York, New York, USA. http://dx.doi.org/10.4135/9781452218557. $\underline{\mathrm{n} 489}$

Papadimos, A., J. Grant, and P. Vajjhala. 2013. Common pitfalls in accountability in social enterprises. Pages 15-38 in T. Lyons, editor. Social entrepreneurship: how business can transform society (Vol. 3) Praeger, Santa Barbara, California, USA.

Parkins, J. R., and D. J. Davidson. 2008. Constructing the public sphere in comprised settings: environmental governance in the Alberta forest sector. Canadian Review of Sociology 45 (2):177-196. http://dx.doi.org/10.1111/j.1755-618X.2008.00009. $\underline{\mathrm{X}}$

Parkins, J. R., S. Nadeau, L. M. Hunt, J. Sinclair, M. G. Reed, and S. Wallace. 2006. Public participation in forest management: results from a national survey of advisory committees. Northern Forestry Centre Information Report NOR-X-409. Northern Forestry Centre, Edmonton, Alberta, Canada.

Reed, M. G., and D. Davidson. 2011. Terms of engagement: the involvement of Canadian rural communities in sustainable forest management. Pages 199-220 in B. Pini and B. Leach, editors. Reshaping gender and class in rural spaces. Ashgate, Aldershot, UK.

Reed, M. G., H. Godmaire, P. Abernethy, and M.-A. Gertin. 2014. Building a community of practice for sustainability: strengthening learning and collective action of Canadian biosphere reserves through a national partnership. Journal of Environmental Management 145:230-239. http://dx.doi.org/10.1016/ j.jenvman.2014.06.030 
Reed, M. G., and K. McIlveen 2006. Toward a pluralistic civic science?: Assessing community forestry. Society and Natural Resources 19(7):591-607. http://dx.doi.org/10.1080/08941920600742344

Reed, M. S. 2008. Stakeholder participation for environmental management: a literature review. Biological Conservation 141:2417-2431. http://dx.doi.org/10.1016/j.biocon.2008.07.014

Reed, M. S., E. D. G. Fraser, and A. J. Dougill. 2006. An adaptive learning process for developing and applying sustainability indicators with local communities. Ecological Economics 59:406-418. http://dx.doi.org/10.1016/j.ecolecon.2005.11.008

Singleton, S. 2002. Collaborative environmental planning in the American West: the good, the bad and the ugly. Environmental Politics 11(3):54-75. http://dx.doi.org/10.1080/714000626

Southwest Nova Biosphere Reserve Association (SNBRA). 2010. Southwest Nova Biosphere Reserve Association strategic plan. SNBRA, Nova Scotia, Canada.

Statistics Canada. 2008. 2006 Community profiles. Statistics Canada, Ottawa, Ontario, Canada. [online] URL: http://www12. statcan.gc.ca/census-recensement/2006/dp-pd/prof/92-591/index. $\underline{\mathrm{cfm} \text { ? Lang }=\mathrm{E}}$

Tietenberg, T. 2002. The tradable permits approach to protecting the commons: what have we learned. Pages 197-232 in E. Ostrom, T. Dietz, N. Dolšak, P. C. Stern, S. Stonich, and E. U. Weber, editors. The drama of the commons. The National Academies Press, Washington, D.C., USA. http://dx.doi.org/10.2139/ $\underline{\operatorname{ssrn} .315500}$

UNESCO. 1996. Biosphere reserves: the Seville Strategy and the statutory framework of the world network. UNESCO, Paris, France.

Yin, R. 2014. Case study research: design and methods. Sage, Thousand Oaks, USA. 